\title{
Responsible Leadership and Intellectual Capital: The Mediating Effects of Effective Team Work
}

\author{
Kalpina Kumari, Sania Usmani, and Javed Hussain
}

\begin{abstract}
In this globalization and competitive era, economy has become more enhanced in terms of productivity, intellectuality, creativity, diversification, threats and new opportunities to avail. Intellectual management can deal these interactions with an effective way to create their value so they could retain their position and goodwill in upcoming competition world. Responsible leadership plays a vital role in converting intrinsic knowledge of employees into intellectual capital of an organization. This research paper positively supports the relationship between the responsible leadership and intellectual capital of an organization and also evidences shows that this relationship is also mediated by an effective teamwork. In order to enhance the performance and productivity of an organization, it is of the immense important for the management to undertake the emphasis on responsible leadership which ultimately enhances to an effective teamwork and intellectual capital of an organization. Personal survey technique has been applied here as a method of data collection and sample size used for this study was 200 respondents. From the research and hypothesis, it can be conclude here that responsible leadership practices play a very important role in order to enhance the performances of teamwork, a long term binding between the leader and team members, intellectuality, and also helps to meet day to day challenges of an organization in more effective way.
\end{abstract}

Index Terms-Responsible leadership, effective teamwork, intellectual capital.

\section{INTRODUCTION}

According to the past perception and understanding by experience, conservative experts suggest that it is intricate to forecast the future with perfection. Instead, Peter Drucker suggests that "In human affairs-political, business or social, economic, -it is useless to attempt to forecast the future, let alone attempt to look ahead 75 years." In spite of this misfortune, Drucker intricacy about credentials indication overhead is optimistic. For firms, it is efficient as well as attainable to distinguish and make it ready for offing that has previously come to pass. Recently, future prediction has become difficult in terms to measure success or failure, so the past events deduce as to how one should get ready for a future whose state has been improved. Accordingly, a description of a responsible leadership on the basis of this approach is provided to aid us to contribute for corporate success throughout the $21^{\text {st }}$ century. Specifically, global economy has created a great influence on responsible leadership already, as it offers feedback about practices that should be employed in future as globalization is irreversible.

To forecast as to how and by what practices a company can

Manuscript received August 17, 2013; revised November 5, 2013.

Kalpina Kumari is with the Iqra University Karachi, Pakistan (e-mail: kalpina@iqra.edu.pk). grow and have greater productivity in the next era, it is essential to identify, investigate and use appropriate leadership strategies which are employed by the visionary leaders of today. It is important to examine these visionary organizations as responsible leadership can prove to be one of the major significant issues in a company. That is when performing globally, the presence of responsible planning ensures the achievement of success and greater productivity. Basically Leadership is an individual's capability to foresee, to visualize, maintaining flexibility, to think tactically, and to bring innovative changes that generates a viable prospect for the firm. The company gains a unique selling point if the competitors fail to understand and replicate a company's strategic leadership. As it is important for all companies to protect their competitive edge, it enables them to implement strategic leadership in a competitive advanced mode allowing the firm's effort to generate higher returns on its venture.

In a nut shell, facing globalization in this century is bound to be difficult, exigent and eventually comprising of aggressive opportunities and threats. Hence, to survive in the market, an effective leadership strategy plays a vital role which aids in enhancing the company's performance while competing in the volatile and chaotic atmosphere.

\section{LITERTURE REVIEW}

\section{A. Responsible Leadership and Intellectual Capital}

One clear similarity between leadership and intellectual capital can easily be identified which target towards the business value. Leadership can lead the business value focusing on innovation and transporting the final results to its stakeholders. While, intellectual capital deals with knowledge distribution within the firm and giving outcomes as to how to create business value [1].

After considering relationship between leadership and intellectual capital, the query remains that as to what extent they share the same meaning and maximize profitability of one another. The high potential in the leadership and intellectual capital can be identified in this relationship, if there is presence of cross-functional teams. High Quality of leadership is considered a major asset for the organizations who desire to see their effective performance in the industry. Poor leadership attributes towards poor assets of an organization, low confidence level, high rate of absenteeism and turnover, slow destruction, increase in dissatisfaction, poor ways of dealing with consumers and markets, poor planning and majorly unexpected results. Share values usually vary evidently when significant leaders connect with any organization or leave them, hence; it is quantifiable in real shareholder value [2].

Leadership is an essential component of an organization as 
it creates a strong influence and affect on other intangible assets. Leadership holds human capital enterprises, primarily. However, when it is understood as a procedure to enhance leadership, it becomes an element of the intellectual capital.

Hence, it leads one's attention to the interaction of human being, their behavior and capital. It displays a positive relationship between strategic leadership \& intellectual capital where strategic leadership improves intellectual capital of an organization, resulting in generating profit by protecting the competitive edge over the competitors in the market.

Intellectual capital is the awareness and skill of an organizations employee. Strategic leaders view organizational employee as worthy resources on which core abilities are developed and competitive benefits are successfully utilized. Globally, to obtain complete competitive edge from the human capital, significant investments are needed which aids in developing intellectual capital of the firm.

Moreover, it increases the efficiency of the employees to work productively. New opportunity of continuous and involvement with community are encouraged by the employees to broaden their knowledge horizon. In order to obtain an innovative and a well educated workforce the continuity of investment is required in organizational employees.

Effective leadership can result in all the above strategies defined, using the accurate and appropriate direction given by the leader can help into accomplish the desired goals. Therefore, this concludes that effective leadership is the most important and critical strategy which helps on carrying out the intellectual capital, resulting in high profit and benefits to different stakeholders.

\section{B. Responsible Leadership and Effective Teamwork}

Strategic leadership and efficient team work can be positively affiliated in an organization. As organizations commonly, boost productivity by assuring effective team work [3]. Teamwork has been a subject of many professionals who believe that it is an influential instrument used by organizations to ensure efficient information sharing. There are two steps involved in achieving this objective, to create a competent team first and then giving them incentives to produce optimum results. Therefore, competent team building triggers and elevates productive team work which will in turn increase the overall efficiency of the organization. New concepts and the process of decision making will be more competent through the efficient use of the variety of skills possessed by the team mates. Hence, attaining synergy but this will only be achieved if the proper incentives are given to them [4].

Furthermore, it is important to answer the query as to who should take charge to build an efficient team and increase their creativity and work performance, and manage them effectively. Highly effective, efficient and creative teams with high cooperation amongst them do not form miraculously. Therefore, the answer lies in building strong leadership strategies in a firm. Successful teams are productive, active, creative and cooperative with each other in order to achieve and resolve issues arising under the effective leadership. Teams are efficient because each individual's capabilities are monitored by their leaders and the teams are made to perform their functions in this way and this will also help in overcoming biasness and influence from those who enforce power on others.

Leaders are the models in directing the teams to the right path in a highly productive manner. Leaders who are accountable or credible lead the organizations globally; keeping in mind the strategy of the firm they are working for and achieve their goals effectively.

They also instruct and strengthen employees to accomplish goals in a moral, considerate and "relationally intelligent" way [5]. Leaders motivate by developing grounds to promote courteous association for group work both within and outside the company, to be answerable to the stakeholders and discourage unethical conduct [6].

The role of leader in cooperate sector is very important for group work [7]. The leader's job is to contribute data and knowledge to meet the objectives with the team, for their success; to create an environment in order to motivate the members to give them a platform where they can yield productive results.

\section{Effective Team Work and Intellectual Capital}

Teamwork has often been employed as a key element in terms of improving learning processes and activities. Group learning acts as a bridge between them, and has always had an authoritative role in both individual and organizational learning. Yet, little importance has been given to the idea that teams as a unit create and utilize knowledge. The past researches channelized their attention merely on the elements that influenced the efficiency and productivity of teams, and thus failed to realize the significance of 'group learning', and how the latter contributes to the process of creating knowledge [8].

Positive organizational rewards result from the ability of an organization to form and impart the knowledge to its employees [9]. It is imperative for an organization to create new knowledge in order to accomplish organizational objectives and to ensure the continuity of the organization in competitive business environment, mainly of firms operating in the fields of science and technology [10]. Firm's knowledge foundation relies on the different ways in which organization members exchange and merge their data, knowledge and thoughts [10]. According to Nahapiet and Ghoshal [9] an organization's capacity of creating a knowledge foundation is the extent to which the top organization team and knowledge workers have the ability of transforming existing information and knowledge into something completely new, and distinguish the value that this process adds to the organization [11].

The concept of exchange information stems out from the idea that the level of information and knowledge varies from individual to individual, and that they can/will pursue teamwork with the objective of learning from each other. The term combination is used to denote the process of merging elements which were not connected to each other before, and of creating new ways to arrange and merge "elements previously unconnected or by developing new ways of combining elements previously associated" [9]. Thus, when brainstorming occurs amongst individuals who vary in levels and types of knowledge, they form new potential facts, which 
prove to be extremely rewarding for the attainment of organizational objectives effectively and efficiently.

\section{MEDIATION MODEL AND HyPOTHESIS}

\section{A. Hypothetical Model of Responsible Leadership,} Effective Team Work, and Intellectual Capital

As the mediating model (Fig. 1), suggests that, responsible leadership can affect intellectual capital of an organization through two different processes. In Fig. 1 the first process clarify the direct positive association between the strategic leadership and intellectual capital of an organization that is revealed when effective team work is held constant. This direct positive relationship implies that high quality of leadership can give rise to high quality of intellectual capital in an organization. On the other side, in Fig. 1 the second process explains again positive but indirect association between strategic leadership and intellectual capital of an organization, mediated by effectiveness of teamwork, which is revealed when teamwork is varied.

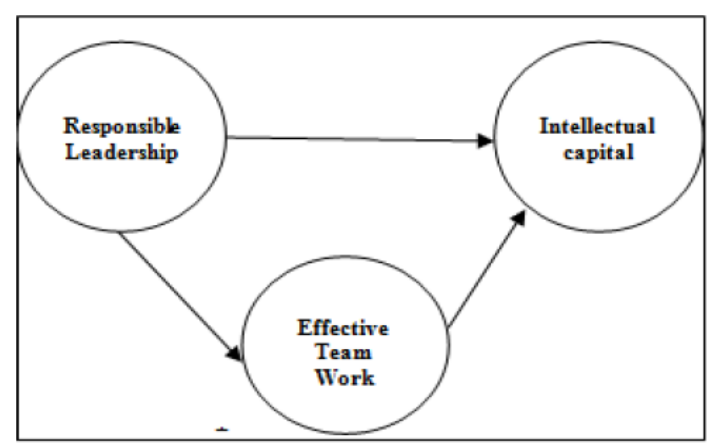

Fig. 1. Causal model of the relationships among responsible leadership, team work, and intellectual capital

So in this causal model the indirect association between the three variables (strategic leadership, effective team work and intellectual capital of an organization) provides the two different indirect connections: strategic leadership is positively associated with effective team work and that effective team work has a positive impact on intellectual capital of an organization.

\section{B. Hypotheses}

H1: There is a positive association between responsible leadership and intellectual capital of an organization.

$\mathrm{H} 2$ : Effective team work mediates the association between responsible leadership and intellectual capital of an organization.

H3: When team work is kept constant, there is an also direct positive effect of responsible leadership on intellectual capital of an organization.

\section{RESEARCH METHODS}

\section{A. Data and Measures}

The sample consisted of customer-service employees of sales department of credit cards working at head offices of Standard Chartered Bank and United bank Limited in Karachi. The responsibilities of sales employee involve marketing and selling credit cards to customers. All of the respondents were full-time employees, selling the same products and services. The reason of selecting only sales department from banking industry was quite straightforward. As in this research study the relationship has been examined between responsible leadership and intellectual capital of an organization, which is mediated by effectiveness of teamwork, so in order to measure this association sufficient sample size was required of those organizations which are practically implemented theses concepts in their organizations or in their particular department in order to achieve their objectives more properly. On the other side, as the accomplishments of sales objectives are totally target based, depending on responsible leadership and how effectively team members are working under the supervision of their leaders, so based on personal judgment, sales department has been chosen for this y research study as its target population.

TABLE I: MEANS, STANDARD DEVIATIONS AND CORRELATIONS AMONG VARIABLE

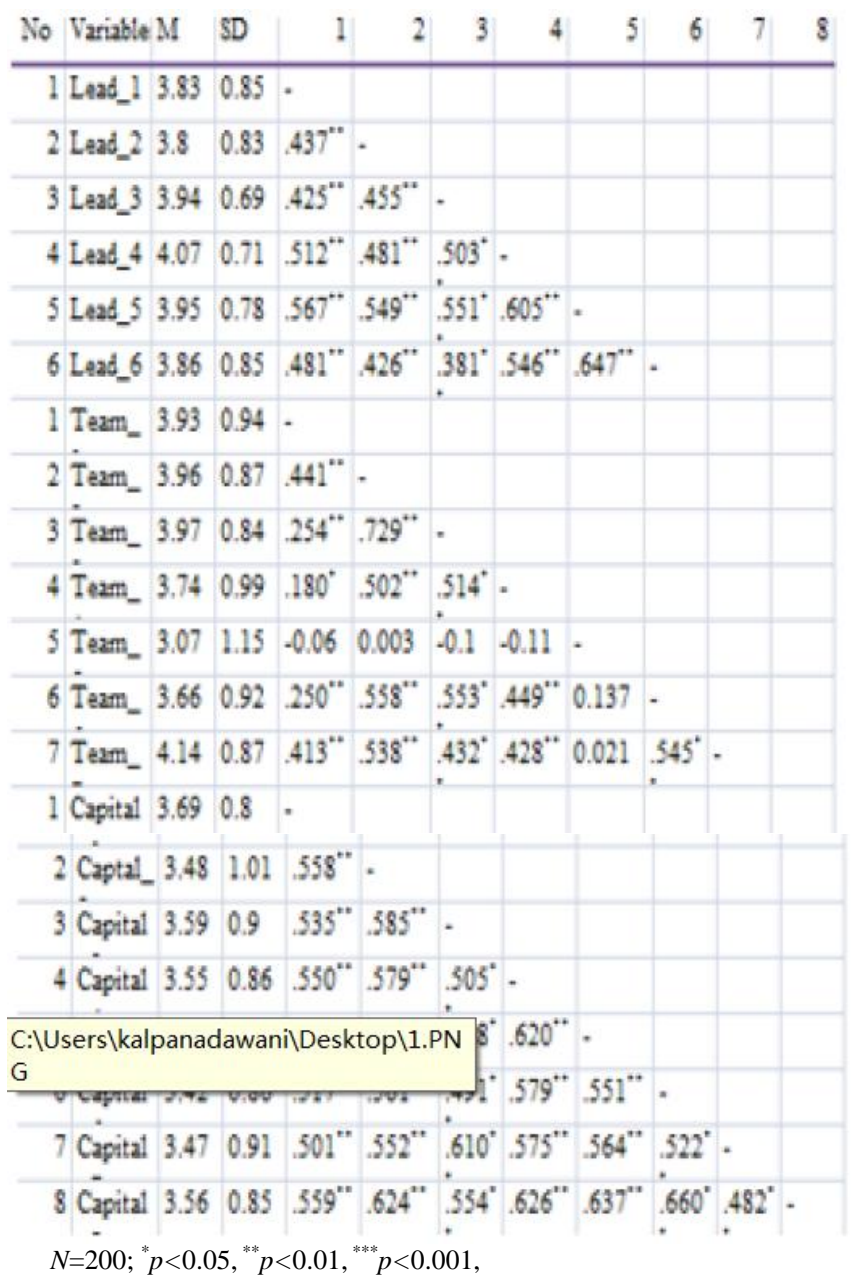

As judgment process has been applied in order to identify target population for this research, so sampling technique would be judgmental non-probability sampling technique. The sampling units consisted of (a) managers or supervisors, (b) team leaders, and (c) the team members. The sample size of the present study consists of 200 employees (120 from head office of Standard Chartered Bank and 80 from head office of United bank Limited). A survey technique was implemented to collect data from the employees. The questionnaires included items responsible leadership, 
effectiveness of teamwork and intellectual capital of an organization.

Responsible Leadership: The measure of responsible leadership was measured with 30 items scale, developed by James A. (Andy) Wood, Bruce E. Winston, (2007). Samples of items included "My leader looks to himself/herself first, when the group's results are disappointing" and "My leader is a role model for me". Its reliability was demonstrated 0.97 . The same scale has been modified in to 6 items scale, as the measurement scale was consists on too many questions.

Effectiveness of Teamwork: The effectiveness of teamwork measure was examined with 29 items scale developed by Stephen J. Lurie, MD, PhD; Stephen H. Schultz MD; Gina Lamanna, MS, (2011). Examples of items included "People in my team actively seek new ways to improve how they do things" and "My team encourages everyone to share ideas". Its reliability was reported 0.84 . The given scale has been modified in to 7 items scale, as the scale was consists on too many questions.

Intellectual Capital: Intellectual capital was assessed by already developed Bontis IC Questionnaire that was consist on 43 items, published in 2001 to measure intellectual capital in organization. Its reliability was reported 0.916 . The developed scale has been modified in to 8 items scale, as the scale was consists on too many questions. Examples of items included "My level of competence as a whole is equal to the most ideal level that my company could ever hope to achieve (matching with my work requirements and responsibilities)" and "I consistently perform at my best level in order to achieve the goals of my organization more efficiently and effectively".

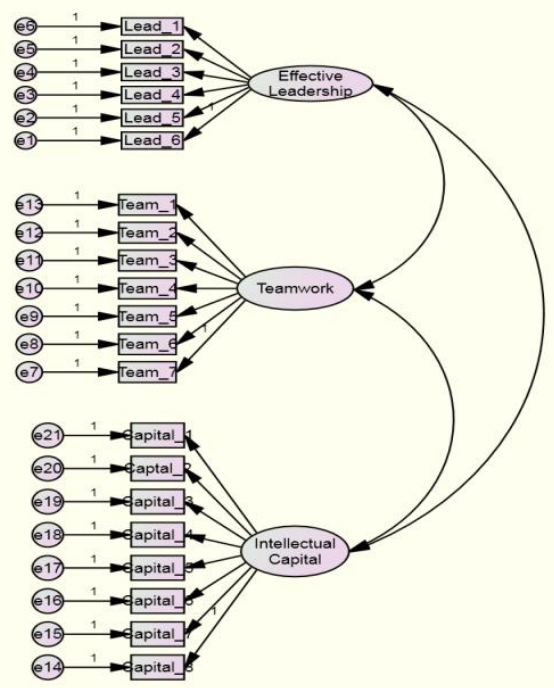

$\mathrm{e}=$ error.

Fig. 2. Theoretical model of confirmatory factor analysis.

\section{RESULTS AND INTERPRETATION}

\section{A. Descriptive Statistics}

Table I reports the descriptive statistics and correlations between all variables and constructs used in the research study. The Cronbach alphas for all constructs showed good levels of reliability, being 0.857 for responsible leadership,
0.74 for effective team work and 0.912 for intellectual capital.

\section{B. Testing the Measurement Model (CFA)}

Based on data from 200 respondents, SEM software has been used to perform Confirmatory factor Analysis, As it has been assumed that data were normally distributed, so maximum likelihood estimation had been chosen. There wasn't found any missing values and as well as multivariate outliers. So the final sample size was 200. Fig. 2 presents the theoretical model of CFA.

The results of CFAs at the first effort were quite supporting the theoretical measurement models posed overall. In the three-factor model, the cutoff values of CMIN/DF, CFI, TLI and RMESHA were quite satisfactory, (Table II), showing a good fit between the model and the observed data (CMIN/DF $=1.561, \mathrm{RMSEA}=0.053, \mathrm{CFI}=0.947, \mathrm{TLI}=0.940$ )

TABLE II: COMPARATIVE SUMMARY OF CONFIRMATORY FACTORS

\begin{tabular}{lrrrr}
\multicolumn{5}{c}{ ANALYSIS } \\
\hline Models & CMIN/DF & \multicolumn{1}{l}{ RMSEA } & \multicolumn{1}{l}{ CFI } & \multicolumn{1}{l}{ TLI } \\
\hline ModelNo:1 & 1.561 & 0.053 & 0.947 & 0.94 \\
ModelNo:2 & 1.416 & 0.046 & 0.967 & 0.962
\end{tabular}

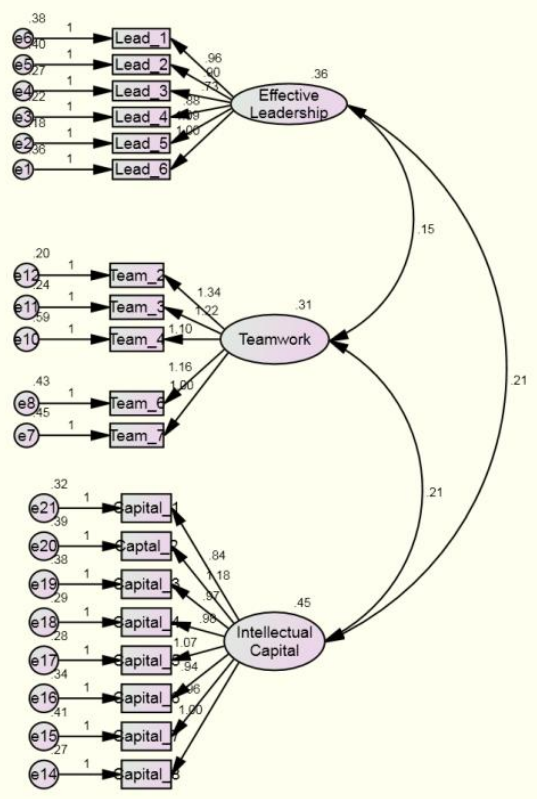

Comparative fit index $=.0 .967$; Tucker-Lewis index $=0.962$; Root mean square error of approximation $=.0 .046$; Chi-square $=211$; degrees of freedom $=$ 149. $\mathrm{e}=$ error

Fig. 2. Hypothesized model of a confirmatory analysis.

But there are two insignificant items (Team_1, Team_5) in the construct of "Team Work" after exploring the values of standardized and unstandarized regression weights (Table III), which should be deleted from the data set. After omitting these two items from data set, the CFA model has turn out to be more considerable comparatively $(\mathrm{CMIN} / \mathrm{DF}=1.416$, RMSEA $=0.046$, CFI $=0.967$, TLI $=0.962$ ), (see the results of Model No: 2, in Table II and see the final theoretical model of CFA, in Fig. 3). 


\section{Validity and Reliability}

It is extremely essential to build convergent and discriminant validity, as well as reliability. When doing a CFA, In order to build validity and reliability, there are a few measures that are very important to be considered: Composite Reliability (CR), Average Variance Extracted (AVE), Maximum Shared Squared Variance (MSV), and Average Shared Squared Variance (ASV). The thresholds for these values are: Reliability: $C R>0.7$, Convergent Validity: $C R>(\mathrm{AVE}), A V E>0.5$, Discriminant Validity: $M S V<\mathrm{AVE}$, $A S V<\mathrm{AVE}$.

TABLE III: COMPOSITE RELIABILITY, CONVERGENT AND DISCRIMINATE

\begin{tabular}{ccccc}
\multicolumn{5}{c}{ VALIDITY } \\
\hline Variables & CR & AVE & MSV & ASV \\
\hline Responsible Leadership & 0.863 & 0.513 & 0.264 & 0.233 \\
Effective Teamwork & 0.864 & 0.561 & 0.328 & 0.265 \\
Intellactual Capital & 0.915 & 0.573 & 0.328 & 0.296 \\
\hline
\end{tabular}

Based on above defined thresholds, it can be concluded over here that all three constructs are having composite reliability (Table III), as their values of CR is greater than 0.7 (Effective Leadership $=0.862$, Teamwork $=0.864$, Intellectual Capital $=0.889)$. On the other hand all three constructs are also meeting the threshold criteria of establishing convergent validity: $C R>A V E>0.5$ and discriminante validities: $A V E>\mathrm{MSV} \& \mathrm{ASV}$ (Effective Leadership $=0.863>0.513>0.5$, Teamwork $=0.864>0.561>$ 0.5 , Intellectual Capital $=0.915>0.573>0.5)$, (Effective Leadership $=0.513>0.264 \& 0.233$, Team work $=0.561>$ $0.328 \& 0.265$, Intellectual Capital $=0.573>0.328 \& 0.296$ ).

\section{Testing a Mediated Model}

In order to test for Hypothesis 1, $2 \& 3$ (the mediated model), full structural equation modeling (SEM) has been implemented, as it has already explained in analysis procedure. The hypothesized model examined the relationship between responsible leadership, effective teamwork and intellectual capital of an organization. The results of the analysis showed good to acceptable fit results (Comparative fit index =. 0.967; Tucker-Lewis index $=0.962$; CMIN/DF $=1.284$; Root mean square error of approximation = 0.046). As explained by Baron and Kenny [12], three different steps were tested in this study: in step no: 1, total effect of responsible leadership on teamwork has been checked, in step no: 2 indirect effect of responsible leadership on intellectual capital through effective teamwork has been assessed and in the last step, only direct relationships between responsible leadership and intellectual capital has been examined, while controlling the impact of effective teamwork which is a mediator.

As from the bootstrap results (Table IV), it is clearly shown that there was significant positive relationship between responsible leadership and intellectual capital $(b=$ $0.581, P<0.05)$ and this positive relationship implied that high quality of responsible leadership can give rise to high quality of intellectual capital in an organization and thus $\mathrm{H} 1$ has been accepted.
TABLE IV: BOOTSTRAP RESULTS OF MEDIATION FROM STRUCTURAL EQUATION MODELING

\begin{tabular}{ccc} 
& \multicolumn{2}{c}{ EQUATION MODELING } \\
\cline { 2 - 3 } Model & \multicolumn{2}{c}{ (Mediator = Effective Teamwork) } \\
& $\mathrm{b}$ & Sig value \\
& & \\
$\begin{array}{l}\text { Direct Effects } \\
\text { Responsible }\end{array}$ & 0.381 & 0.00 \\
$\begin{array}{c}\text { Leadership } \\
\text { Indirect Effects } \\
\begin{array}{c}\text { Responsible } \\
\text { Leadership } \\
\text { Total Effects } \\
\text { Responsible }\end{array}\end{array}$ & 0.20 & 0.00 \\
Leadership & 0.581 & 0.00 \\
\hline
\end{tabular}

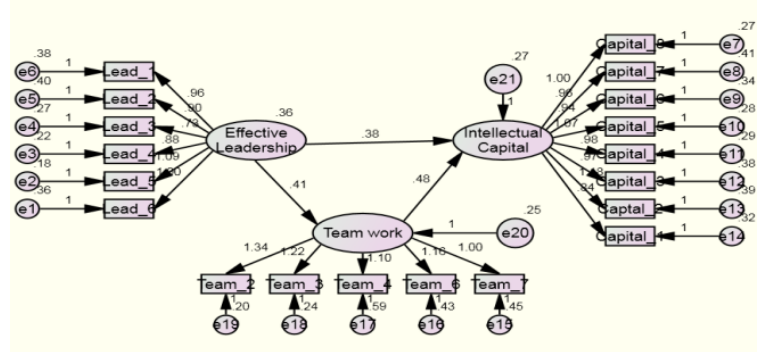

Comparative fit index $=.0 .967 ;$ Tucker-Lewis index $=0.962 ;$ CMIN/DF $=$ 1.284; Root mean square error of approximation $=0.046, \mathrm{e}=$ error.

Fig. 4. Results of the structural equation model.

Now as concern to findings regarding teamwork that whether it mediates the positive relationship between responsible leadership and intellectual capital or not, bootstrap results of indirect effect (see the results of indirect effects in Table IV and see mediating final hypothesized model in Fig. 4), were showing strong evidences that teamwork mediated the positive relationship between responsible leadership and intellectual capital $(\mathrm{b}=0.20, \mathrm{P}<$ $0.05)$. Thus $\mathrm{H} 2$ of this study has also been accepted and it indicates that mediation between the strategic leadership and intellectual capital of an organization through teamwork has been established. This relationship explained that if any organization has a competitive advantage over other competitors in the industry based on the strategic leadership, which in turn can enable the organization to produce high productive results through ensuring effectiveness of teamwork. Afterwards the resulted effective teamwork will again help out the leaders to enhance the intellectual capital of the same organization, so the overall efficiency and effectiveness of an organization will increase.

While the mediator effect of effective teamwork has been controlled, the direct relationship between responsible leadership and intellectual capital was significant as well $(\mathrm{b}=$ $0.381, \mathrm{P}<0.05)$, which indicated that when team work is held constant, there is a direct positive effect of responsible leadership on intellectual capital of an organization and thus 
H3 of this study have been accepted. This analysis suggests that effective teamwork partially mediates the relationship between responsible leadership and intellectual capital.

\section{CONCLUSION}

The analysis carried out based on empirical data gathered; shows that responsible leaders not only can establish an effective teamwork but can also enhance an intellectual capital of an organization as well. The survey also shows that in progressive cooperatives, leaders with a knowledge management mindset have woven developmental activities into the organization and achieved the spectacular results from the ordinary members reflecting in their increased participation.

The main purpose of this research paper was to highlight the importance of responsible leadership in association with the intellectual capital and effective teamwork in an organization. So It can be concluded based on the study that leadership creates a social relation within the ethical framework of organization. It establishes an interaction between the leader and the group of his followers which enhances the interest, intellectuality and motivation of employees towards their own responsibilities of work. The followers are the leader's stakeholders, who either work in close supervision of leader or took active part in leadership projects. Often, they have an equivalent status. I therefore contended in this globalization and networking environment the concept of leader in common language is, he is known as the head of the family or the great man at the top of pyramid, is no longer appropriate because leader are also considered as human being who earns a license to guide their followers and helps to retain them on the right path. A leader play a vital role in bringing up new talent of employees on single platform, and motivate their followers in achieving common goals, builds their internal interest towards their work and helps to retain them within an organization. At last they need values and moral character which will help to enhance the relation of teamwork and helps to overcome complex challenges in future which will benefit for organization in achieving their targets.

The real strength of any cooperative entity is its inner strength originates from the cohesiveness and commitment of its members. Cooperatives are inward looking organizations and hence member centrality is the crux of any cooperative enterprise that upholds cooperative identity. Cooperatives succeed only when they are member driven. Members can drive a cooperative only when they are 'Developed Members', equipped with the vital ingredients such as knowledge, commitment, values, good human relationship and trust on the cooperative cause. In other words, it is this internal intellectual capital, an empowered factor of production that facilitates cooperative to deliver. This indeed necessitates a paradigm shift both in the leadership focus and the management strategy that underpin talent management of member capital in the cooperatives. The leaders should support the members through their human resource activities that reflect on stable, motivated and loyal member base on which in turn can create intellectual capital for the same organization and thus can lead towards a bright and successful future.
This study showed that leaders had been positively responsible for the improved competencies and overall organizational commitment for the effective teamwork which in turn has played a significant role in enhancing an overall intellectual capital of an organization. The concept of a dynamic environment and its concerned contingency planning techniques are now a vital part of managerial success in $21^{\text {st }}$ century. In particular human resource along with responsible leadership has gained immense significance in contemporary management practices. However it is quite astonishing that several of our human resource development and management practices are still the same, based on the rigid structures of old hierarchy and leadership. Managers must learn to analyze the subordinates associated with them in order to recognize their overall capabilities and their desires and lead them accordingly. Nowadays generation are usually innovative, charismatic, know how to adapt to new things, have a capability to mould things according to different situations, believe in teamwork, and they have an intrinsic drive to achieve their respective targets. Therefore there should have to be comprehensive leadership strategies which would allow their subordinates to maximize their potentials and will ultimately contribute to an enhanced intellectual capital of an organization. So managers are required to make new effective work methodologies and leadership practices as the contemporary generation and teenagers are not willing and motivated to work on old school philosophies of management.

The major implication of this research for training and management systems is that employees need to be empowered and given the accurate environment to attain their fullest potential. In order to mange those empowered employees strong responsible leadership is essential to attain organizational excellence and excellent organizations constantly strive to develop strong leadership skills in all subordinates. In an outstanding organization, the many operational responsibilities work together to achieve a core mission while striving to succeed and develop to fulfill new challenges. Outstanding organizations have a dream, smooth organizational practices, incorporated knowledge sharing systems, great flexibility, motivated employees, a distinctive and optimistic culture, and greater performance towards unambiguous goals and objectives. In an excellent organization, employees are focused to be satisfied and fulfilled. All theses underlined goals and characteristics of excellent organizations can only be meet and fulfilled through responsible leadership only because leadership is essentially the core and spirit of successful organizations.

\section{REFERENCES}

[1] R. S. Kaplan and D. P. Norton, Strategy Maps - Converting Intangible Assets into Tangible Outcomes, Boston, Harvard Business School Press, 2004.

[2] A. Mayo, The Human Value of the Enterprise - Valuing People as Assets - Monitoring, Measuring, Managing, Brealey Publishing, London, 2001.

[3] Papers for You. (2006). P/HR/245. Team work: Theory and case study. [Online]. Available: http://www.coursework4you.co.uk/sprthrm3.htm

[4] S. P. Robbins and M. Coulter, Management, Sixth Edition, New Jersey: Prentice- Hall Inc., 2002.

[5] N. M. Pless and Th. Maak, "Relational intelligence for leading responsibly in a connected world," in K. M. Weaver (ed.), Proceedings of the Sixty-fifth Annual Meeting of the Academy of Management, Honolulu, HI, 2005. 
[6] R. E. Freeman, A. C. Wicks, and B. Parmar, "Stakeholder theory and the corporate objective revisited," Organization Science, vol. 15, no. 3, pp. 364-369.

[7] A. F. Laidlaw, "Cooperatives in the year 2000," A paper presented for the 27th congress of the ICA Moscow, October. London: ICA, 1980.

[8] J. C. Navarro and B. R. Moya, "Learning facilitating factors of teamwork on intellectual capital creation," Knowledge and Process Management, vol. 12, pp. 32-42, 2005.

[9] J. Nahapiet and S. Ghoshal, "Social capital, intellectual capital, and the organizational advantage," Academy of Management Review, vol. 23, pp. 242-266, 1998.

[10] B. Kogut and U. Zander, "Knowledge of the firm, combination capabilities, and the replication of technology," Organization Science, vol. 3, pp. 383-397, 1992.

[11] C. Collins and K. Smith, "Knowledge exchange and combination: The role of human resource practices in the performance of high-technology firms," Academy of Management Journal, vol. 49, pp. 544-560, 2006.

[12] R. M. Baron and D. A. Kenny, "The moderator-mediator variable distinction in social psychological research: Conceptual, strategic, and statistical considerations," Journal of Personality and Social Psychology, vol. 51, pp. 1173-1182, 1986.

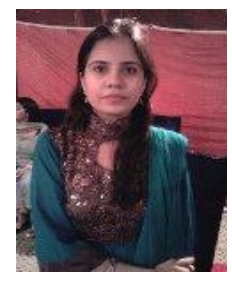

Kumari Kalpina was born in Karachi, Pakistan on $19^{\text {th }}$ of June 1985 . The author's has completed B.com from Karachi University in 2004 with first class division and then completed MBA in Human Resource management from Iqra University with 3.36 CGPA. Currently doing PhD from Iqra University in Management and has completed all courses with 3.4 CGPA. Simultaneously she is working as a Lecturer at Iqra University in Management Sciences Department, Main Campus, Karachi, Pakistan and teaching multiple courses as a permanent faculty member such as Writing Research Report, Principles of Marketing, and Self-management Skills to BBA \& MBA Classes. Her Research Interests are in the field of HR management. 